Artículo

\title{
Caracterización y agrupamiento de cebadas imberbes mediante sensores infrarrojos y rendimiento de forraje
}

\author{
María Alejandra Torres Tapia ${ }^{1}$ \\ Víctor Manuel Zamora Villa ${ }^{2 \S}$ \\ Modesto Colín Rico ${ }^{2}$ \\ Rahim Foroughbakhch Pournavab ${ }^{1}$ \\ Maginot Ngangyo Heya ${ }^{1}$
}

${ }^{1}$ Facultad de Ciencias Biológicas-Universidad Autónoma de Nuevo León. Ave. Pedro de Alba s/n cruz con Ave. Manuel L. Barragán, San Nicolás de los Garza, Nuevo León, México. (atorres_tapia@hotmail.com; rahim.forough@gmail.com; nheyamaginot@yahoo.fr). ${ }^{2}$ Departamento de Fitomejoramiento-Universidad Autónoma Agraria Antonio Narro. Calzada Antonio Narro 1923, Col. Buenavista, Saltillo, Coahuila. México. CP. 25315. (modesto.colin@uaaan.mx).

${ }^{\S}$ Autor para correspondencia: zamora2602@yahoo.com.mx.

\section{Resumen}

En el noreste de México es necesario tener variedades de cebada adaptadas a climas extremos como alternativa en la producción de forraje. Para la estimación de biomasa, existen sensores infrarrojos remotos que no han sido aplicados en cebadas forrajeras. Los objetivos fueron caracterizar, agrupar y seleccionar líneas de cebada forrajera imberbe, y estimar la asociación de sensores con el rendimiento. Se evaluaron 45 líneas contra variedades comerciales en dos municipios del estado de Coahuila, durante el otoño-invierno 2016-17; se realizó un diseño alfa-látice con tres repeticiones, se determinó rendimiento de forraje, altura de planta, etapa fenológica, y como sensores infrarrojos un termómetro IP-54, un GreenSeeker ${ }^{\mathrm{TM}}$ para índice de vegetación diferencial normalizado (NDVI) y un SPAD-420 para contenido de clorofila; evaluando en dos muestreos. Se realizó un análisis parcelas subdivididas para variables, correlaciones para estimación de relación y un análisis de multivariados por muestreo. Los resultados indicaron diferencias altamente significativas en rendimiento entre genotipos, localidades e interacciones. Las líneas 6, 43, 44, 40 y 1 presentaron características deseables de producción forrajera. El análisis de conglomerados a 75 y 90 dds retuvo cinco y siete grupos de interés respectivamente, marcando diferencias entre grupos en la prueba de $\mathrm{T}^{2}$, formando grupos diferentes en variedades comerciales y líneas. No se detectó una asociación positiva y significativa entre NDVI y rendimiento para los genotipos estudiados. Los métodos multivariados resultaron herramientas útiles para seleccionar líneas forrajeras de rápida producción. Afirmando a las cebadas como una buena opción para la producción forrajera en épocas invernales en zonas semiáridas, en comparación de avena y trigo.

Palabras clave: cebada sin arista, rendimiento de materia seca, NDVI.

Recibido: marzo de 2019

Aceptado: julio de 2019 


\section{Introducción}

Los cereales de invierno son una alternativa sostenible para la producción ganadera, debido al uso eficiente del agua a pesar de la creciente frecuencia de heladas por el cambio climático. Sin embargo, existe entre ellos una competencia de utilización en los sistemas intensivos pecuarios (Colín et al., 2009; Calderón et al., 2015). En México, la cebada además de ser el principal insumo en la industria cervecera tiene la alternativa de emplearse como forraje, para pastoreo, para ensilaje o para ser cosechado tanto en grano como en follaje verde (Newman y Newman, 2008; Zamora et al., 2017).

La cebada tiene ventajas interesantes sobre otros cereales del mismo ciclo, es más vigorosa, resistente a sequía y a la salinidad, puede cultivarse en suelos marginales (Colín et al. 2007; 2009; Keles et al., 2013; Wilson et al., 2017). Se ha documentado que la cebada igual que otros cereales de invierno presenta altos rendimientos, son ricos en proteínas, vitaminas e hidratos de carbono (Cherney y Marten, 1982; Cash et al., 2004) y en particular la cebada, no disminuye tanto su calidad forrajera en etapas posteriores a la antesis, probablemente debido a la mayor cantidad de grano (Colín et al., 2007, 2009).

Para mantener o incrementar la producción de forraje de cebada, se requiere seleccionar nuevos genotipos, métodos de producción eficaces, sostenibles y que se adapten a los cambios climáticos (Nelson et al., 2009), además se deben considerar características deseables para el productor en sistemas intensivos como: precocidad, altura de planta y alto rendimiento de forraje seco.

En la evaluación de la producción de biomasa o materia seca aérea, normalmente se realizan muestreos o cortes del forraje, pero recientemente se ha desarrollado un método de muestreo indirecto y no destructivo mediante el uso de sensores infrarrojos conocido como índice de vegetación diferencial normalizado (NDVI), teniendo un alto porcentaje de coincidencia con la producción en trigo y maíz (Verhulst et al., 2010; Bastidas et al., 2016); sin embargo, en cebada no se ha estudiado esta relación, tampoco con la temperatura del dosel y contenido de clorofila, ni la posible correlación entre estos y con la producción de biomasa total como en otras especies (Medina et al., 2009; Freeman et al., 2007; Chavez et al., 2017; Castro et al., 2011; Zajac et al., 2013).

Esta investigación tuvo como objetivos el caracterizar, agrupar y seleccionar líneas de cebada forrajera sin aristas y estimar la asociación de sensores infrarrojos entre sí y con rendimiento de materia seca de esta especie.

\section{Materiales y métodos}

Se estableció el estudio en dos localidades del estado de Coahuila de Zaragoza: Ejido San Lorenzo, Municipio San Pedro de las Colonias (localidad 1) y el Campo experimental de la Universidad Autónoma Agraria Antonio Narro en el Municipio de Zaragoza (Localidad 2), durante el ciclo otoño-invierno 2016-17. San Lorenzo se ubica a $25^{\circ} 43^{\prime} 26^{\prime \prime}$ ' de latitud norte y $103^{\circ} 09^{\prime} 12^{\prime \prime}$ longitud oeste, a una altitud de $1090 \mathrm{msnm}$, con clima muy árido y semicálido, con temperatura entre $18{ }^{\circ} \mathrm{C}$ (mes más frío) y $22{ }^{\circ} \mathrm{C}$ (mes más caliente), lluvias de verano de 5 a $10 \%$ anual con $181 \mathrm{~mm}$. La localidad de Zaragoza está ubicada a $28^{\circ} 30$ latitud norte y $100^{\circ} 55^{\prime}$ longitud oeste, con una altitud $360 \mathrm{msnm}$, con clima árido y cálido; temperatura media anual mayor de $22^{\circ} \mathrm{C}$, lluvias entre verano e invierno mayores a $18 \%$ anual entre 300 a $400 \mathrm{~mm}$ (Arriaga et al., 2000). 
Se evaluaron 45 líneas progenies de cebada forrajera imberbe, producto de la cruza entre la variedad GABYAN95 con la variedad comercial Esperanza, utilizando como testigos una avena (cv. Cuauhtémoc), una cebada maltera (cv. Cerro prieto), la cebada forrajera (cv. GABYAN95), un triticale de grano (cv. Eronga-83), adicionalmente una línea experimental de trigo (AN-266-99). Estos genotipos se establecieron en un diseño alfa-látice con tres repeticiones, considerando la parcela experimental de $5.4 \mathrm{~m}^{2}$ (6 surcos de $3 \mathrm{~m}$ de longitud, espaciados a $0.3 \mathrm{~m}$ ).

La preparación del terreno consistió en las labores tradicionales en las regiones, bajo condiciones de riego, realizando el barbecho, rastreo y nivelación, sembrando en seco, manualmente y a chorrillo, a una densidad de $100 \mathrm{~kg} \mathrm{ha}^{-1}$. A la siembra se aplicaron 80 unidades de fósforo utilizando fosfato monoamónico (MAP) y 60 unidades de nitrógeno usando urea. En el primer riego de auxilio se aplicaron otras 60 unidades más de nitrógeno. Las malezas se controlaron con 2,4-D amina a una dosis de $1.5 \mathrm{~L} \mathrm{ha}^{-1}$, no se aplicó fungicida o insecticida.

En ambas localidades se realizó un riego de siembra y tres riegos auxiliares. La lámina total aproximada durante el ciclo del cultivo fue de $40 \mathrm{~cm}$. Se realizaron dos muestreos a 75 y 90 días después de la siembra, cortando con una hoz $50 \mathrm{~cm}$ de una hilera con competencia completa, seccionando a una altura aproximada de $5 \mathrm{~cm}$ sobre la superficie del suelo. Las muestras de forraje verde cosechado se colocaron en bolsas de papel y se secaron en una estufa de aire forzado a $65^{\circ} \mathrm{C}$ por 48 horas, posteriormente se pesaron y se determinó el rendimiento de forraje seco en gramos (materia seca), transformando en toneladas por hectárea (REND), al momento del corte se registraron las variables: altura de la planta en centímetros (ALTURA), temperatura de dosel en grados Celsius (TEMP), índice de concentración de clorofila (ICC), índice de vegetación diferencial normalizado (NDVI) y la etapa fenológica (ETAPA) de acuerdo a la escala de Zadocks et al. (1974).

La TEMP se determinó con un termómetro infrarrojo IP-54, marca Fluke, con mira laser, señalando en la parte media de cada parcela experimental. Para medir el ICC, se utilizó un clorofilómetro SPAD-420, marca Konica Minolta, tomando la lectura en la parte media de 10 hojas banderas de cada parcela. El NDVI, se midió a través de un sensor portátil, marca GreenSeeker ${ }^{\mathrm{TM}}$, evaluando en la parte central de cada parcela.

La información se analizó mediante un diseño de parcelas subdivididas con arreglo en bloques al azar, considerando las localidades como parcela grande, los muestreos como parcela mediana y los genotipos como parcela chica, las medias se compararon utilizando la prueba DMS al $0.05 \%$ de probabilidad mediante el uso del paquete SAS (SAS, 1989).

Posteriormente se obtuvieron las correlaciones fenotípicas entre pares de variables. Con las medias de los genotipos; a través, de las localidades, se realizaron análisis multivariados de componentes principales (ACP) y conglomerados (AC) para cada muestreo realizado, el análisis de componentes principales con el fin de reducir la dimensionalidad de los datos, detectar asociaciones entre variables y la caracterización parcial de los genotipos (Manly, 1986). Se realizó el análisis de conglomerados para conformar grupos de genotipos similares entre si y distintos a los de otros grupos, estos análisis se realizaron con el programa Statistica (Statistica, 1994), para decidir sobre la significancia entre los grupos generados se utilizó la prueba de $\mathrm{T}^{2}$ de Hotteling (Jhonson y Wichern, 1988). 


\section{Resultados y discusión}

El análisis de varianza mostró diferencias altamente significativas entre genotipos y localidades para TEMP, NDVI, ALTURA, ICC y REND; de igual forma en la interacción genotipos por localidad mostró diferencias altamente significativas en todas las variables mencionadas y en la interacción genotipos por muestreo en las variables ALTURA, ICC y NDVI se encontraron también diferencias $(p \leq 0.01)$, mientras que en REND y TEMP no se reportaron diferencias.

Al jerarquizar los factores y considerar las localidades como parcela grande al momento del análisis de datos, fue en reconocimiento a la importancia de las condiciones ambientales y su gran influencia en la producción (Shao et al., 1995), sobre todo por cambios de temperatura que se pueden presentar en las áreas agrícolas, generando un impacto en la distribución, fenología y fisiología del cultivo y hasta en el rendimiento de los cultivos (Wahid et al., 2007; Jarvis et al., 2008), lo que pudiera haber sido el factor que provocó la diferencia significativa entre las localidades de evaluación.

Las diferencias entre los muestreos, reflejaron el efecto que el tiempo y fenología impusieron a los genotipos en la mayoría de las variables evaluadas excepto el REND, debido parcialmente por la precocidad de la especie de cebada (Colín et al., 2007, 2009; Domínguez et al., 2016), ya que en general se observó de un muestreo a otro, el incremento de TEMP, ALTURA, ICC y ETAPA combinado con menor NDVI, coincidiendo con otros autores que a etapas tempranas los valores de NDVI son bajos, llega a una etapa donde el valor máximiza y disminuye en etapas más tardías (Teal et al., 2006; Freeman et al., 2007).

En las interacciones localidades por muestreo y localidades por genotipo se detectaron comportamientos diferenciales, refrendados por la significancia de la triple interacción sobre todo en NDVI e ICC evaluados con los sensores ópticos por primera vez en estos materiales forrajeros imberbes y que sugieren un estudio detallado de la interacción genotipo ambiente en estas variables. Las comparaciones de medias confirmaron que la localidad 1 (San Pedro de las Colonias, Coahuila), destacó por la mayor respuesta el REND, ETAPA, ICC y NDVI combinado con menor TEMP, mientras, que el efecto de la temperatura y otros factores del ambiente resultó más evidente en Zaragoza, Coahuila (localidad 2), posiblemente provocando una ligera degradación de la clorofila reflejado en los valores bajos del ICC obtenidos en esta localidad.

Es posible que la temperatura haya acelerado la fenología de los genotipos (Karsai et al., 2008), lo cual se reflejó en los menores contenidos ICC, como se ha reportado en líneas mutantes de trigo duro (Spano et al., 2003). Se conformaron 12 grupos de significancia para la variable TEMP, encontrando los genotipos $17,5,13,1,2,3,32,4$ y 25 con valores promedios por arriba de $24.2^{\circ} \mathrm{C}$, formando el primer grupo; similarmente se formaron 13 grupos en REND sobresaliendo los genotipos 43, 6, 44, 19, 25, 1, 11, 23, 2 y 21 con una producción entre 11.7-12.8 $\mathrm{t} \mathrm{ha}^{-1}$ dentro de los 25 genotipos del primer grupo, confirmando la amplia adaptación de la cebada (Nelson et al., 2009), aún en condiciones áridas y semiáridas mencionadas por Sadeghpour et al. (2013), coincidiendo con Domínguez et al. (2016) en el alto índice de biomasa en cebada comparada con trigo y triticale.

Prosiguiendo con la comparación de medias, se obtuvieron 19 grupos tanto en NDVI como en ALTURA, destacando en la primera variable, los testigos trigo AN-266-99 y GABYAN95 con los valores más altos (0.79 y 0.76 de NDVI respectivamente), y en los genotipos 33, 32, 36, 35, 19, 6, 
8, 29, 34 y 4 al haber mostrado alturas superiores de $107.92 \mathrm{~cm}$, en el ICC reportó al testigo avena con el mayor índice (54.61 unidades Spad). La avena (cv Cuauhtémoc), trigo (AN-266-99) y triticale (cv Eronga-83) por su parte, presentaron mayor NDVI e ICC, pero menor REND.

Debido que en los sistemas intensivos de producción de forraje se requieren genotipos precoces y la diferencia entre muestreos reportada por el análisis de varianza, se analizó por separado la información de dos muestras usando métodos multivariados, el análisis de componentes principales (ACP) para el primer muestreo a 75 dds, explicó $63.82 \%$ de la varianza total con los dos primeros componentes principales (CP), el CP1 contuvo 39.95\% de la varianza y con los dos primeros componentes se generó la Figura 1, permitió visualizar en el primer cuadrante una relación positiva de las variables TEMP, REND y ALTURA entre sí y positiva con ambos componentes, teniendo mayor asociación ALTURA (0.89) con el primer componente, seguido por REND y ETAPA.

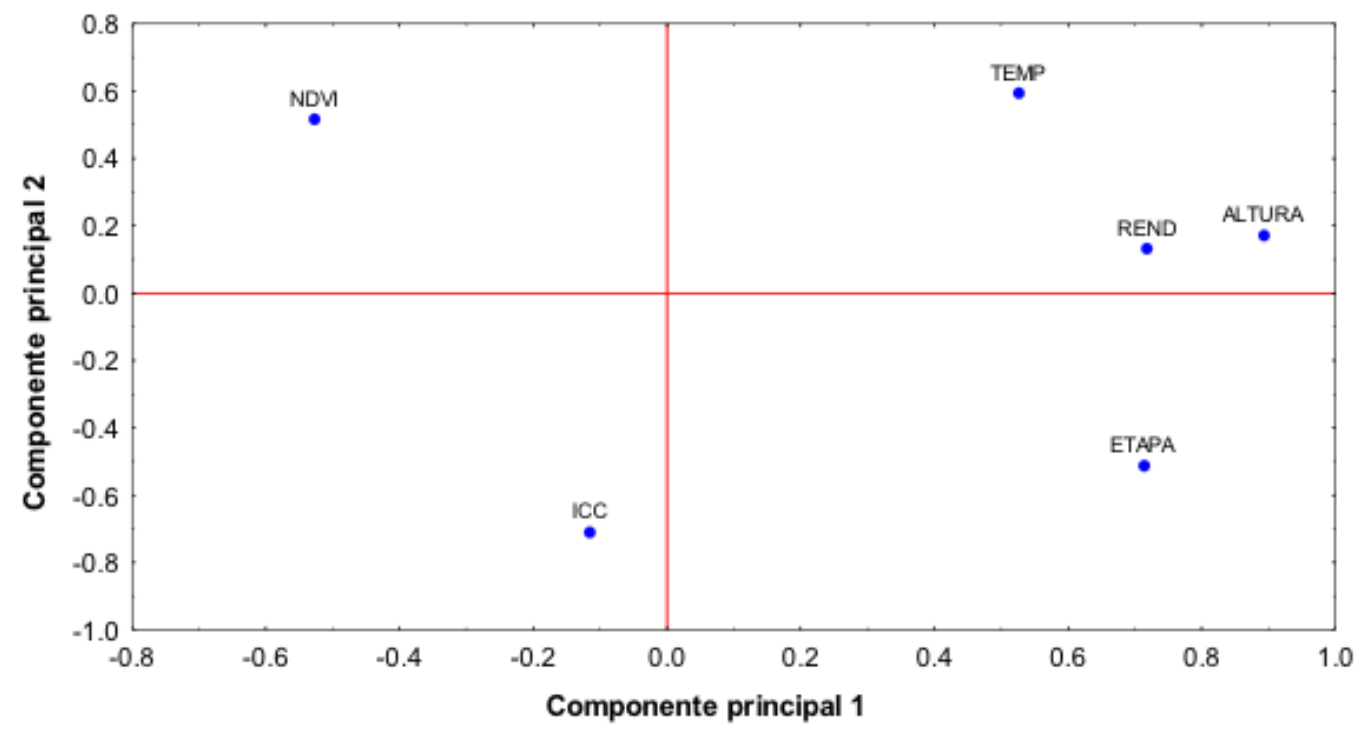

Figura 1. Relaciones entre las variables evaluadas en el plano de los dos componentes principales en un primer muestreo (75 días).

Esto sugiere que el CP1 es un componente de producción, precocidad y morfología, que puede realizar una separación entre los genotipos con mayor rendimiento de forraje seco, más precoces y altos que presentan también mayor temperatura del dosel, pero con menor NDVI e ICC.

El segundo CP separa genotipos más precoces y con mayor ICC de aquellos con mayor NDVI, TEMP, ALTURA y rendimiento de forraje seco. La relación detectada por este componente (CP2) sugiere la existencia de genotipos que pudiesen presentar el stay green, dado que a mayor etapa fenológica mantienen aún un contenido de clorofila alto.

Este ACP para el primer muestreo permitió detectar la relación inversa entre el rendimiento de materia seca y el NDVI que en otros cultivos se ha reportado positiva y significativamente relacionado con la producción de biomasa (Teal et al., 2006; Freeman et al., 2007; Raun et al., 2008); sin embargo, en cebada parece no ocurrir o verse muy afectada por la precocidad de ésta especie, lo cual pudiera relacionarse también con la menor cantidad de clorofila, tal como la ha sugerido Spano et al. (2003). 
En la Figura 2, se visualizan los genotipos en el plano generado por los dos primeros CP, donde en el primer cuadrante los genotipos 1, 6, 19, 29, 32 y 33 entre otros, presentan el mayor rendimiento de forraje seco, altura de planta y temperatura, en el segundo cuadrante se ubicaron los genotipos 25, 37, 44, 41, 42, 43 y 45 siendo considerados los más precoces. En el tercer cuadrante se ubicaron los genotipos 7, 14 y los testigos triticale y avena presentando el mayor ICC; mientras avena y los genotipos 7 y 14 se ubicaron cercanos al siguiente cuadrante con valores altos de ICC y NDVI. En el cuarto cuadrante se ubicaron Cerro prieto, GABYAN95 y trigo, así como los genotipos 11, 12, 13, 16 entre otros, teniendo los mayores valores de NDVI, pero menos rendidores y tardíos a los 75 dds.

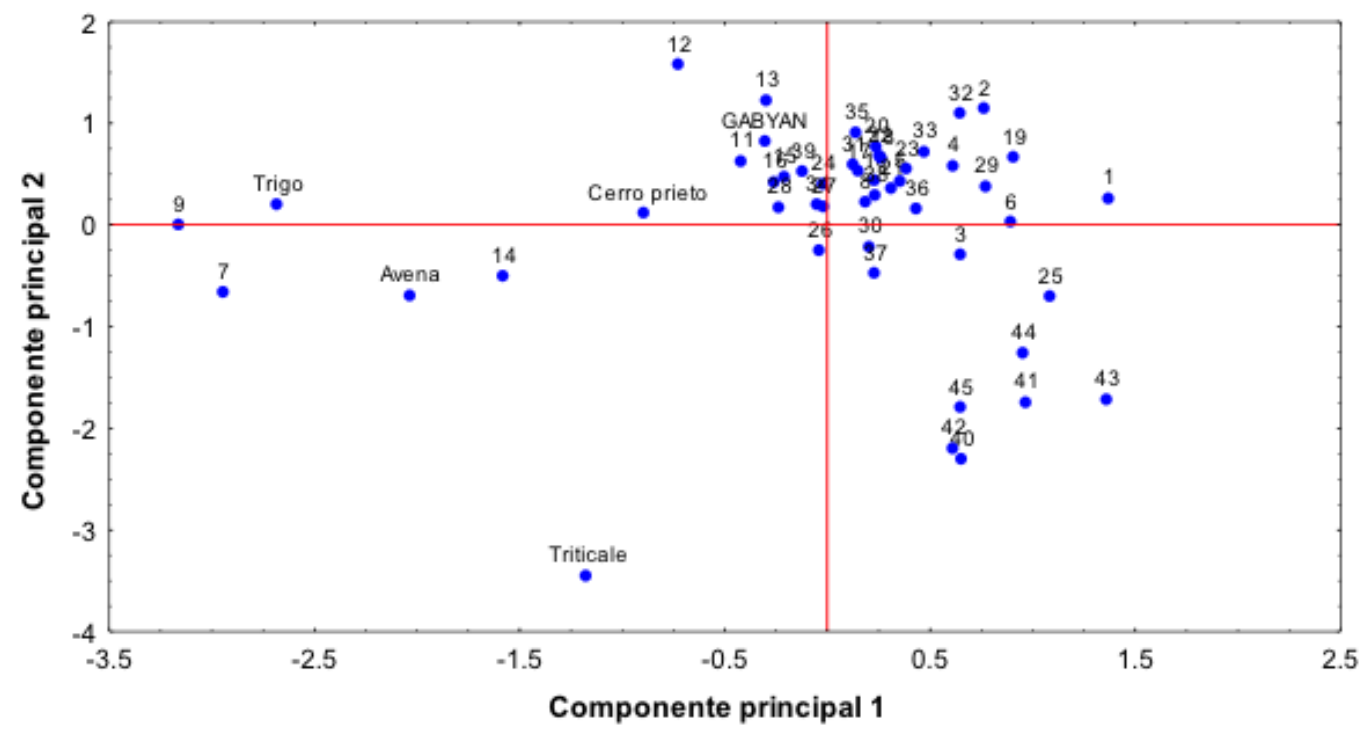

Figura 2. Distribución de genotipos en el plano de los dos componentes principales en un primer muestreo (75 días).

Algunas progenies de cebada forrajera mostraron ser superiores a su progenitor (GABYAN95) en TEMP, ALTURA, ETAPA y REND, lo cual permite la selección preliminar de genotipos como el 40, 41, 42, 43, 44, 45, 25 y 1, que con base a su producción son opciones potenciales para producir adecuada cantidad de forraje a los 75 dds. Se asienta una selec ción preliminar dado que falta conocer su composición nutricional y otros parámetros para hacer la selección final, aunque se ha definido la etapa de embuche para obtener una mayor calidad de forraje en los cultivos de cereales (Espitia et al., 2012; Flores et al., 2016), donde cebada no es la excepción (Colín et al., 2007, 2009).

Con el fin de clarificar las relaciones detectadas por el ACP se realizaron correlaciones de Pearson entre pares de variables, las cuales mostraron que la ALTURA fue la variable que más se asoció con otras, pues mantuvo asociación positiva y significativa con la TEMP $(r=0.51)$, con el REND ( $\mathrm{r}=0.61)$ y con la ETAPA $(\mathrm{r}=0.51)$, pero se relacionó negativa y significativamente con el NDVI ( $\mathrm{r}=-0.31)$, confirmando las relaciones detectadas por el ACP plasmadas en la Figura 1 , donde se apreció lo aquí mencionado. Para el ICC no se encontraron asociaciones significativas en esta etapa. 
La ETAPA se asoció positiva y significativamente con el REND ( $\mathrm{r}=0.32$ ), pero negativa y significativamente con el NDVI ( $\mathrm{r}=-0.51)$. se puede establecer que, para este grupo de materiales, a los 75 dds el rendimiento de forraje está influenciado por mayor etapa fenológica, mayor altura de planta, mayor temperatura del dosel. Estos resultados reafirman lo reportado por Colín et al. (2007), respecto a la relación entre el REND, ALTURA y ETAPA encontrados en cebada.

Del análisis de conglomerados (AC) realizado a los 75 dds, se retuvieron cinco grupos, que la prueba de $\mathrm{T}^{2}$ declaró diferentes entre sí, los cuales que permitieron establecer que la avena y el triticale (Grupo 4), se comportaron muy diferente de las cebadas evaluadas, en tanto que el trigo se agrupó con los genotipos de cebada 7, 9 y 14 conformando el grupo 2, indicando un comportamiento similar.

En este aspecto el AC mostró ser una herramienta efectiva para separar estas especies e identificar genotipos de cebada con comportamiento similares. Por su parte, los testigos Cerro prieto y GABYAN95 se agruparon junto con 29 genotipos más de cebada forrajera imberbe en el grupo 1, otros 6 genotipos de cebada formaron el grupo 3 por poseer características muy similares, al igual que aquellos que integraron el grupo 5 (Cuadro 1). Todos los grupos fueron diferentes entre sí desde el punto de vista multivariado.

Cuadro 1. Número de integrantes (n), media y desviación estándar de los grupos generados por el análisis de conglomerados a un primer muestreo de 75 días.

\begin{tabular}{lccccc}
\hline \multirow{2}{*}{ Variable } & Grupo 1 & Grupo 2 & Grupo 3 & Grupo 4 & Grupo 5 \\
\cline { 2 - 6 } & 31 & 4 & 6 & 2 & 7 \\
\hline Temperatura & $21.2 \pm 0.24$ & $20.5 \pm 0.457$ & $20.7 \pm 0.197$ & $20.4 \pm 0.082$ & $20.9 \pm 0.197$ \\
NDVI & $0.8 \pm 0.009$ & $0.81 \pm 0.012$ & $0.78 \pm 0.008$ & $0.8 \pm 0.065$ & $0.78 \pm 0.009$ \\
Altura & $98.5 \pm 3.867$ & $65.8 \pm 8.305$ & $98.8 \pm 2.97$ & $85 \pm 0$ & $98.9 \pm 2.955$ \\
ICC & $42.67 \pm 1.365$ & $43.26 \pm 1.98$ & $45.57 \pm 1.023$ & $51.97 \pm 0.46$ & $41.69 \pm 1.104$ \\
Rendimiento & $11 \pm 1.052$ & $8.7 \pm 0.505$ & $11.4 \pm 0.929$ & $9.7 \pm 2.302$ & $11.9 \pm 1.053$ \\
Etapa & $43.9 \pm 1.777$ & $37.3 \pm 2.872$ & $54.8 \pm 2.23$ & $39 \pm 5.657$ & $43.6 \pm 0.787$ \\
\hline
\end{tabular}

$\mathrm{Al}$ analizar las características de los grupos, se pudo realizar una caracterización más completa de sus integrantes y con ello una selección preliminar, de forma que si se desean genotipos con mayor rendimiento de forraje y mayor altura de planta y una etapa de embuche, pudieran ser ideales los genotipos pertenecientes al grupo 5, pero si se deseara hacer un corte de forraje más temprano (menor de los 75 días), los genotipos del grupo 3 son aún más precoces, con un rendimiento de 11.4 $\mathrm{t} \mathrm{ha}^{-1}$ de forraje seco y la segunda mayor cantidad de clorofila. Estos dos grupos reúnen las características detectadas por el ACP relacionadas con un mayor rendimiento de forraje seco, objetivo primario en el mejoramiento de forrajeras.

Avena y triticale (grupo 1), se comportaron más tardíos que las cebadas, mostrando altura de planta y rendimientos aceptables, temperatura fresca y mayores contenidos de clorofila (ICC), aunque esto no se reflejó en un mayor valor de NDVI. Lo anterior, sustenta la afirmación de que las cebadas forrajeras representan una buena opción en la producción de forraje a un tiempo más corto que los testigos de otras especies, reafirmando la precocidad de la especie cebada (Domínguez et al., 2016), siendo alternativa para la producción de forraje temprano en las zonas semiáridas (Colín et al., 2007, 2009; Sadeghpour et al., 2013). 
Para el segundo muestreo realizado a los 90 días, el ACP explicó 66\% de la varianza total con los dos primeros componentes principales (CP). El primer CP contuvo $44.21 \%$ de la varianza, ubicando a la variable NDVI en el primer cuadrante con una relación positiva en ambos $\mathrm{CP}$, en el segundo cuadrante se identificó al ICC con relación positiva en el CP1 y negativa con el CP2 (Figura 3). Este componente puede interpretarse como de rendimiento y apariencia, dado que del lado derecho identifica los genotipos de mayor verdor, pero ligados a menor rendimiento, altura, etapa y temperatura.

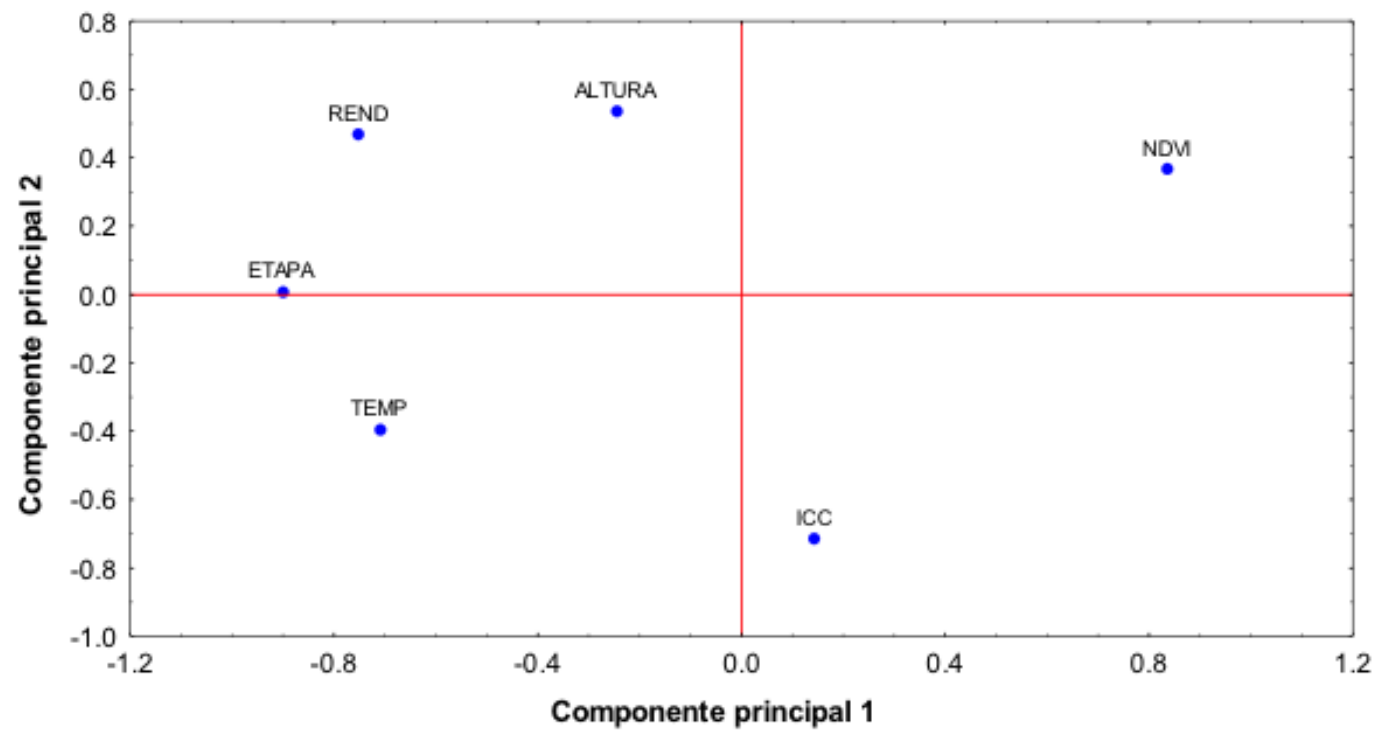

Figura 3. Relaciones entre las variables evaluadas en el plano de los dos componentes principales en un segundo muestreo (90 días).

El segundo componente contuvo $21.79 \%$ de la varianza y sugiere que la TEMP presentó una relación negativa con el resto de las variables ubicándola en el tercer cuadrante (Figura 3). En este segundo muestreo, se mantuvo la relación positiva entre el rendimiento de forraje seco (REND) con la ETAPA, ALTURA y TEMP reportadas en el primer muestreo. Se mantuvo también la relación negativa detectada por el ACP entre el NDVI y el forraje seco producido a los 90 dds, lo cual es contrario a lo reportado en otras especies (Teal et al., 2006; Freeman et al., 2007; Raun et al., 2008). Se reafirma que el primer $\mathrm{CP}$ es un componente de producción, precocidad y morfología.

La Figura 4 muestra los genotipos en el plano generado con los dos CP, para su respectiva caracterización parcial, así, ubicados en el primer cuadrante los testigos trigo y GABYAN95 y los genotipos $10,15,22,23,33,34,35,37,38$ y 39, presentaron valores altos del NDVI a los 90 dds, mientras que en el segundo cuadrante se ubicaron aquellos de mayor contenido de clorofila, comprendiendo los testigos Cerro prieto, triticale, avena, además de los genotipos 7, 9, 12, 14 y 16. En este muestreo también se encontraron progenies que mostraron valores superiores al progenitor GABYAN95 en las variables de ETAPA, REND, ALTURA y TEMP, sobresaliendo genotipos como el 6, 43, 44, 40 y 1, resaltando que, excepto el genotipo 6, los genotipos restantes mantuvieron este comportamiento desde el primer muestreo, con la ventaja de no presentar aristas en la espiga (Flores, 1977; Colín et al., 2009). 


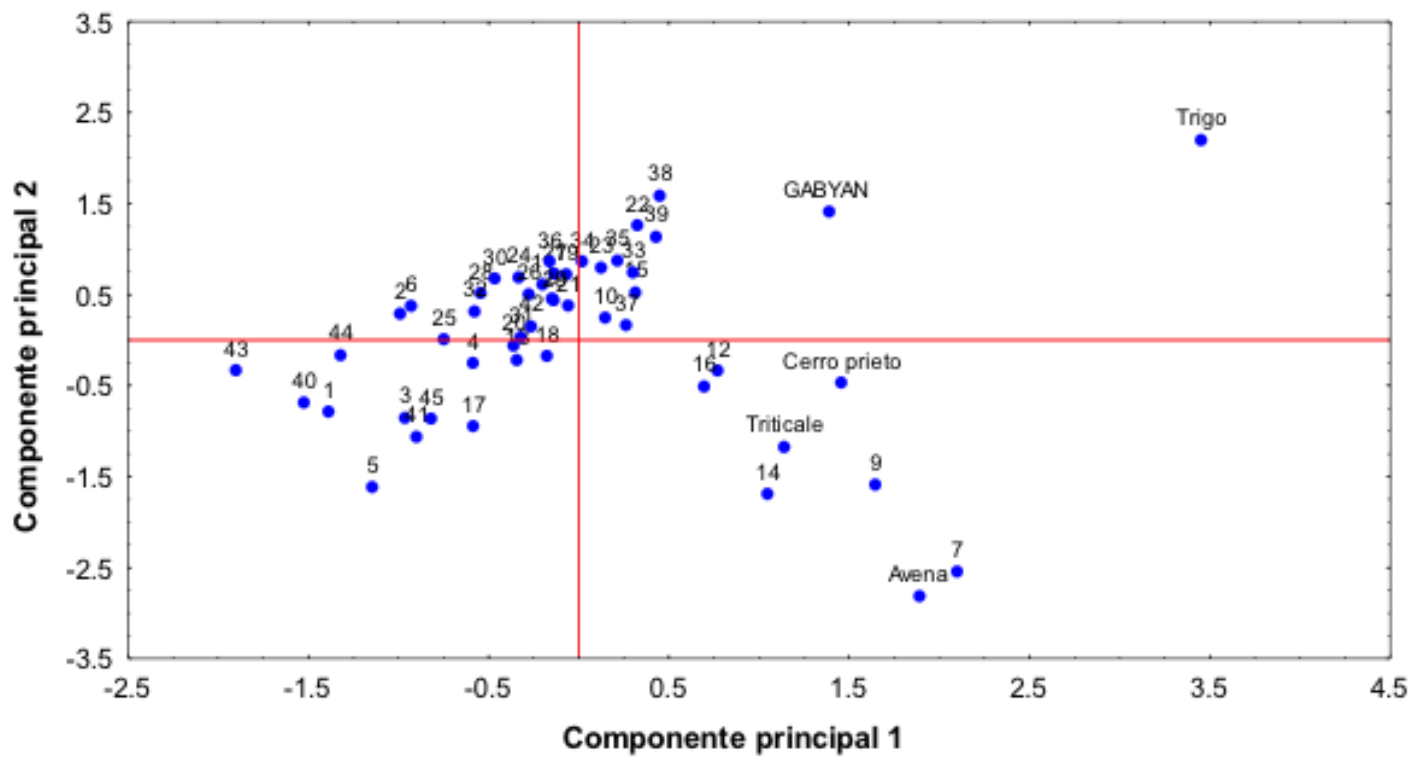

Figura 4. Distribución de genotipos en el plano de los dos componentes principales en un segundo muestreo (90 días).

En el tercer cuadrante se ubicaron a los genotipos 1, 4, 5, 17, 18, 19, 40, 43, 44 y 45 caracterizados por mayor TEMP y REND, ALTURA y ETAPA, en el cuarto cuadrante se encontraron el resto de los genotipos con valores de mayor REND, ALTURA y ETAPA. El trigo se ubicó en una posición distante del resto de los genotipos evaluados, presentando mayor NDVI, pero siendo más tardío (baja ETAPA) y con menor REND en comparación con las cebadas evaluadas, afirmando en ello, la relación que existe entre los rangos de NDVI, la fenología del cultivo y el rendimiento (De la Casa et al., 2007; Grohs et al., 2009; Lara y Gandin, 2015). Además, que en este segundo muestreo destacaron algunos genotipos de cebada forrajera imberbe como el 6, 2, 43, 44, 40 y 1 por presentar mayor rendimiento de forraje, altura de la planta y precocidad.

Las correlaciones estimadas en este segundo muestreo mostraron que todas las variables estudiadas se relacionaron significativamente con el rendimiento de forraje seco, así la ALTURA, ETAPA y TEMP se relacionaron positivamente con REND en magnitudes de $r=0.3, r=0.64$ y $r=0.29$, respectivamente; pero se relacionó negativamente con el NDVI $(\mathrm{r}=-0.4)$ y el contenido de clorofila $(\mathrm{r}=-0.34)$. La TEMP tuvo una relación negativa y significativa con el NDVI $(\mathrm{r}=-0.63)$, pero positiva y significativa la ETAPA $(r=0.48)$.

Se resalta aquí la asociación negativa y significativa entre el NDVI con el REND ( $r=-0.4)$, que en otras especies ha sido reportada como asociada positivamente con el rendimiento de materia seca (Teal et al., 2006; Freeman et al., 2007; Raun et al., 2008) y que justifica la realización de estudios específicos en cebada para determinar si el NDVI puede ser utilizado en la predicción de REND, dado que en este estudio solo se realizaron dos determinaciones del mencionado índice. Las correlaciones afirmaron los resultados del ACP y confirmaron la relación significativa y negativa entre el NDVI con el rendimiento de materia seca (REND), que desde el primer muestreo evidenciaba la mencionada relación. 
En el segundo muestreo se retuvieron siete grupos de interés de los reportados por el análisis de conglomerados, ya que el AC ubicó al trigo como único integrante del grupo 5, separado del resto de los genotipos estudiados. Al igual que en el muestreo anterior, el testigo avena y triticale conformaron un grupo (grupo 4, del Cuadro 2) y fueron los de mayor ALTURA y ICC, menor REND y los segundos más tardíos después del trigo, el Grupo 7 lo conformaron la variedad Cerro prieto y las progenies 12 y 16 de cebada forrajera, con ALTURA similar al Grupo 1 pero con REND bajo, en este muestreo las progenies 7, 9 y 14 se comportaron como cebadas tardías (grupo 2).

Al igual que en el primer muestreo, el AC en este segundo muestreo separó efectivamente a los testigos de otra especie, confirmando el comportamiento diferente de las cebadas forrajeras respecto a estos testigos y demostrando que el AC puede utilizarse como herramienta en la selección de genotipos. Los genotipos de cebada forrajera imberbe más rendidores y precoces se ubicaron en el grupo 1 (Cuadro 2), que a los 90 dds se encontraban en la etapa de grano lechoso, constituyéndose, así como uno de los grupos deseables para seleccionar, en tanto que el resto de las forrajeras imberbes se agruparon en los grupos 3 (mitad de la floración) y 6 (inicio de floración), estos últimos grupos con rendimientos similares.

Este diferencial en las etapas de las cebadas, además de mostrar parte de la variablidad que posee la especie, representa opciones para la producción de forraje, pues comparativamente con la avena que se encontraba al inicio de espigamiento, puede significar el ahorro de un riego cuando se pretende cosechar el forraje con algo de grano (Colín et al., 2009)

Otros como avena y triticale (grupo 4) se encontraban en una etapa de emergencia de espiga, con la mayor altura de planta, pero con bajos rendimientos de forraje. Se enfatiza la comparación de los nuevos genotipos contra la avena, dado que la avena sigue siendo la más utilizada en la producción de forraje invernal y se desea establecer que algunos genotipos de cebada son opciones viables para los esquemas intensivos de producción de forrajes. Si se desea seleccionar genotipos de cebada forrajera imberbe de más altura, el grupo 6 mostraron ser los más altos entre las cebadas, en este grupo se encontró la variedad GABYAN95 todos con buena precocidad, no tan avanzada que los grupos 1, pero similar al grupo 3 y más precoz que los grupos 2, 4, 5 y 7 .

Cuadro 2. Número de integrantes (n), media y desviación estándar de los grupos generados por el análisis de conglomerados en el segundo muestreo de 90 dds.

\begin{tabular}{lccccccc}
\hline \multirow{2}{*}{ Variable } & Grupo 1 & Grupo 2 & Grupo 3 & Grupo 4 & Grupo 5 & Grupo 6 & Grupo 7 \\
\cline { 2 - 8 } & 10 & 3 & 12 & 2 & 1 & 19 & 3 \\
\hline TEMP & $27.3 \pm 0.317$ & $26.8 \pm 0.357$ & $27.3 \pm 0.34$ & $26.7 \pm 0.507$ & $25 \pm 0$ & $26.7 \pm 0.27$ & $26.5 \pm 0.328$ \\
NDVI & $0.55 \pm 0.028$ & $0.64 \pm 0.02$ & $0.59 \pm 0.015$ & $0.63 \pm 0.028$ & $0.77 \pm 0$ & $0.63 \pm 0.029$ & $0.62 \pm 0.052$ \\
Altura & $108 \pm 3.384$ & $83 \pm 0.12$ & $112 \pm 2.714$ & $121 \pm 1.178$ & $105 \pm 0$ & $114 \pm 2.845$ & $108 \pm 2.887$ \\
ICC & $48.4 \pm 0.846$ & $48.4 \pm 1.119$ & $46.3 \pm 0.814$ & $55.4 \pm 2.223$ & $44.9 \pm 0$ & $46.4 \pm 0.842$ & $47.7 \pm 1.937$ \\
REND & $11.9 \pm 1.053$ & $8.5 \pm 0.962$ & $10.8 \pm 0.682$ & $7.9 \pm 1.406$ & $9.4 \pm 0$ & $10.8 \pm 0.504$ & $8.4 \pm 0.472$ \\
Etapa & $72.3 \pm 1.585$ & $53.3 \pm 4.933$ & $64.6 \pm 4.124$ & $52.5 \pm 4.950$ & $43 \pm 0$ & $63.7 \pm 3.656$ & $60.8 \pm 3.175$ \\
\hline
\end{tabular}

De nueva cuenta el análisis de conglomerados permitió una caracterización más completa de los grupos, coincidiendo con Colín et al. (2007) quienes ubicaron en diferente grupo tanto al cultivo de avena como al triticale. Se confirma lo reportado por Colín et al. (2009), respecto a que las cebadas forrajeras imberbes tienen más precocidad y rendimiento entre los cereales de grano pequeño. 
Como se mencionó anteriormente, éste diferencial en las etapas fenológicas alcanzadas por las cebadas, además de mostrar parte de la variabilidad que posee la especie, representan opciones para la producción de forraje, pues comparativamente con la avena, puede significar el ahorro de un riego cuando se pretende cosechar el forraje con algo de grano, como ocurre en las explotaciones intensivas de las zonas semiáridas (Colín et al., 2007; Sadeghpour et al., 2013).

\section{Conclusiones}

Se confirmó el efecto que imponen las localidades en la producción de forraje seco de los genotipos evaluados, así como el referente a las etapas de muestreo. Los métodos multivariados resultaron un apoyo eficiente para entender las relaciones entre variables y proporcionar una caracterización parcial de los genotipos evaluados, permitiendo inclusive seleccionar por características deseables. Entre los grupos formados existen genotipos imberbes de cebada forrajera deseables para la producción rápida de forraje en invierno como son $6,43,44,40$ y 1.

En los materiales evaluados no se detectó una asociación positiva entre el NDVI y la producción de forraje seco evaluado a través de los muestreos realizados en las localidades utilizadas. De acuerdo con este estudio, se observó que las cebadas forrajeras por su precocidad son una alternativa para la producción de forraje durante el invierno.

\section{Agradecimientos}

Se hace un especial agradecimiento a la Universidad Autónoma Antonio Narro por el apoyo brindado en la realización de este trabajo de investigación. Asimismo, a la SEP-SES por el apoyo convencional nacional para estudios de doctorado núm. 6690/18.

\section{Literatura citada}

Arriaga, L.; Espinoza, J. M.; Aguilar, C.; Martínez, E.; Gómez, L. y Loa, E. 2000. Regiones terrestres prioritarias de México. Comisión Nacional para el Conocimiento y Uso de la Biodiversidad (CONABIO) México, DF. 611 p.

Bastidas, A.; Barahona, R. and Cerón, M. 2016. Variation in the normalized difference vegetation index (NDVI) in dairy farms in northern Antioquia. Livestock Research for Rural Development. Volume 28, Article \#43. Retrieved January 16, 2018, from http://www.lrrd.org/lrrd28/3/bast28043.html.

Calderón, G. J.; Monterroso, R. A. y Gómez, D. J. 2015. Cambio climático en el centro de México: impacto en la producción de cebada (Hordeum vulgare) en Tlaxcala. Ra Ximhai. 11(5):37-46.

Cash, S. D.; Staber, L. M. M.; Wichman, D. M. and Hensleigh, P. F. 2004. Forage yield, quality and nitrate concentration of barley grown under irrigation. Montana State University. 4 p.

Castro, R. R.; Hernández, G. A.; Aguilar, B. G. y Ramírez, R. O. 2011. Comparación de métodos para estimar rendimiento de forraje en praderas asociadas. Naturaleza y Desarrollo 9(1):38-46.

Chávez, C. E.; Paz, P. F. y Bolaños, G. M. A. 2017. Estimación de biomasa y cobertura aérea usando radiometría e imágenes digitales a nivel de campo en pastizales y matorrales. Terra Latinoam. 35(3):247-257. 
Cherney, J. H. and Marten, G. C. 1982. Small grain crop forage potential: I. biological and chemical determinants of quality, and yield. Crop. Sci. 22(2):227-231.

Colín, R. M.; Zamora, V. V. M.; Lozano del R, A. J.; Martínez, Z. G. y Torres, T. M. A. 2007. Caracterización y selección de nuevos genotipos imberbes de cebada forrajera para el norte y centro de México. Téc. Pec. Méx. 45(3):249-262.

Colín, R. M.; Zamora, V. V. M.; Torres, T. M. A. y Jaramillo, S. M. A. 2009. Producción y valor nutritivo de genotipos imberbes de cebada forrajera en el norte de México. Téc. Pec. Méx. 47(1):27-40.

De la Casa, A. and Ovando, G. 2007. Normalized difference vegetation index (NDVI) and phenological data integration to estimate country yield of corn in Córdoba, Argentina. Agric. Téc. 67(4):362-371.

Domínguez, M.; López, C. L. E.; Benítez, R. C. I. y Mejía, C. J. A. 2016. Desarrollo radical y rendimiento en diferentes variedades de trigo, cebada y triticale bajo condiciones limitantes de humedad del suelo. Terra Latinoam. 34(4):393-407.

Espitia, R. E.; Villaseñor, M. H. E.; Tovar, G. R.; Olán, M. y Limón, O. A. 2012. Momento óptimo de corte para rendimiento y calidad de variedades de avena forrajera. Rev. Mex. Cienc. Agríc. 3(4):771-783.

Flores, M. J. A. 1977. Bromatología animal. Edición Limusa. México. 1096 p.

Flores, N. M. de J.; Sánchez, G. R. A.; Echavarría, Ch. F. G.; Gutiérrez, L. R.; Rosales, N. C. A. y Salinas, G. H. 2016. Producción y calidad de forraje en mezclas de veza común con cebada, avena y triticale en cuatro etapas fenológicas. Rev. Mex. Cienc. Pec. 7(3):275-291.

Freeman, K. W.; Girma, K.; Arnall, D. B.; Mullen, R. W.; Martin, K. L.; Teal, R. K. and Raun, W. R. 2007. By-plant prediction of corn forage biomass and nitrogen uptake at various growth stages using remote sensing and plant height. Agron. J. 99(2):530-536. doi: 10.2134/agronj2006.0135.

Grohs, S. D.; Bredemier, C.; Mundstock, M. C. y Poletto, N. 2009. Modelo para estimativa do potencial produtivo em trigo e cevada por medio do sensor GreeSeeker. Eng. Agríc. Jaboticabal. 29(1):101-112.

Jarvis, A.; Lane, A. and Hijmans, R. 2008. The effect of climate change on crop wild relatives. Agr. Ecosyst. Environm. 126(1):13-23.

Jhonson, R. A. and Wichern, D. W. 2007. Applied multivariate statistical analysis. $6^{\text {th }}$ (Ed.). Upper Saddle River, NJ, USA. Prentice-Hall. ISBN 0-13-187715-1. 767 p.

Karsai, I.; Szucs, P.; Kõszegi, B.; Hayes, P.M.; Casas, A.; Bedõ, Z. and Veisz, O. 2008. Effects of photo and thermo cycles on flowering time in barley: a genetical phenomics approach. J. Exp. Bot. 59(10):2707-2715.

Keles, G.; Ates, S.; Coskun, B. and Koc, S. 2013. Re-growth yield and nutritive value of winter cereals. Proceedings of the $22^{\text {nd }}$ International Grassland Congress. Sídney Australia. ISBN: 9781742565439. 951-953. pp.

Lara, B. Y. y Gandini, M. 2016. Caracterización del comportamineto fenlógico de las coberturas vegetales en un sector de la Pampa Deprimida (Argentina): una aproximación utilizando series temporales de NDVI. Ambiência Guarapuava (PR). 12(14):765-783.

Manly, B. F. J. 1986. Multivariate statistical methods: a primer. London: Chapman and Hall. London-New York. ISBN: 0-412-28610-6. 159 p.

Medina, G.; Gutiérrez, R.; Echavarría, F.; Amador, M. y Ruiz, J. 2009. Estimación de la producción de forraje con imágenes de satélite en los pastizales de Zacatecas. Téc. Pec. Méx. 47(2):135-144. 
Nelson, C.; Rosegrant, M.; Koo, J.; Robertson, R.; Sulser, T.; Zhu, T.; Ringler, C.; Msangi, S.; Palazo, A.; Batka, M.; Magalhaes, M.; Valmonte-Santos, R.; Ewing, M. y Lee, D. 2009. Cambio climático: el impacto en la agricultura y los costos de adaptación. Instituto Internacional de Investigación sobre políticas alimentarias IPFRI. 30 p.

Newman, R. K. and Newman, W. C. 2008. Barley history: relationship of humans and barley through the ages. In: Newman, R. K. and Newman, C. W. Barley for food and health. science, technology and products. John Wiley \& Sons, Inc (Ed.). New Jersey. ISBN: 9780-470-10249-7. 243 p.

Raun, W. R.; Solie, J. B.; Taylor, R. K.; Arnall, D. B.; Mack, C. J. and Edmon, D. E. 2008. Ramp calibration strip technology for determining midseason nitrogen rates in corn and wheat. Agron. J. 100(4):1088-1093.

Repková, J.; Brestič, M. and Olšovská, K. 2009. Leaf growth under temperature and light control. Plant Soil Environ. 55(12):551-557.

Sadeghpour, A.; Jahanzad, E.; Esmaeili, A.; Hosseini, M. B. and Hashemi, M. 2013. Forege yield, quality and economic benefit of intercropped barley and anual medic in semi-arid conditions: Additive series. Field Crops Res. 148(79:43-48.

SAS. 1989. Institute Inc. SAS/STAT User's guide. Versión 6. Fourth edition. SAS Institute Inc., Cary, NC.

Shao, G. and Halpin, P. N. 1995 Climatic controls of eastern North American coastal tree and shrub distributions. J. Biogeography. 22(6):1083-1089.

Spano, G.; Di Fonzo, N.; Perrota, C.; Platani, C.; Ronga, G.; Lawlor, D. W.; Napier, J. A. and Shewry, P. R. 2003. Physiological characterization of 'stay green' mutants in durum wheat. J. Exp. Bot. 54(5):1415-1420.

Statistica, 1994. Statistica for windows (ver. 4.5) Tulsa Ok, USA: StatSoft, Inc.

Teal, R. K.; Tubana, B.; Girma, K.; Freeman, K. W.; Arnall, D. B.; Walsh, O. and Raun, W. R. 2006. In-season prediction of corn yield potential using normalized difference vegetation index. Agron. J. 98(10):1488-1494.

Verhulst, N.; Govaerts, B. y Fuentes, P. M. 2010. Sensor portátil GreenSeekerTM para la medición del índice diferencial de vegetación normalizado (NDVI): una herramienta para la evaluación integral de las prácticas agronómicas. Parte A: conceptos y estudios de caso. México, DF. Centro Internacional del Maíz y Trigo (CIMMYT). El Batán, Estado de México. 13 p.

Wahid, A.; Gelani, S.; Ashraf, H. and Foolad, M. R. 2007. Heat tolerance in plants: an overview. Environm. Exp. Botany. 61(3):199-223.

Wilson, G. C. Y.; Hernández, G. A.; Ortega, C. M. E.; López, C. C.; Bárcena, G. R.; Zaragoza, R. J. L. y Aranda, O. G. 2017. Análisis del crecimiento de tres líneas de cebada para producción de forraje, en el valle de México. Rev. FCA UNCUYO. 49(2):79-92.

Zadocks, J. C.; Chang, T. T. and Konzak, C. F. 1974. A decimal code for the growth stages of cereals. Weed Res. 14(12):415-421. Doi:10.111/j.1365-3180.1974.tb01084.x.

Zajac, C. C.; Vallejos, A. G.; Zajac, E. E. y Galantini, J. 2013. Análisis del rendimiento en cereales de invierno mediante mapas de rendimiento y el índice de vegetación de diferencia normalizada (NDVI) en el Sudoeste Bonaerense, Argentina. Chilean J. Agric. Anim: Sci., ex Agro-Ciencia. 29(2):95-102.

Zamora, D. M.; Pérez, R. J.; Huerta, A. R.; López, C. M.; Gómez, M. R. y Rojas, M. I. 2017. Maravilla: variedad de cebada forrajera para Valles Altos de México. Rev. Mex. Cienc. Agríc. 8(6):1449-1454. 